\title{
Assessment of the family environment in pediatric neurodisability: a state-of-the-art review
}

\author{
Marjolijn Ketelaar, Aline Bogossian, Michael Saini, Anne Visser- \\ Meily, and Lucyna Lach
}

\author{
Version Publisher's PDF \\ Citation Ketelaar, M., Bogossian, A., Saini, M., Visser-Meily, A., \& Lach, L. \\ (published version) (2016). Assessment of the family environment in pediatric \\ neurodisability: A state-of-the-art review. Developmental Medicine \& Child \\ Neurology, 59(3), 259-269. doi:10.1111/dmcn.13287 \\ Copyright/License $\mathrm{n} / \mathrm{a}$ \\ Publisher's Statement n/a
}

How to cite TSpace items

Always cite the published version, so the author(s) will receive recognition through services that track citation counts, e.g. Scopus. If you need to cite the page number of the author manuscript from TSpace because you cannot access the published version, then cite the TSpace version in addition to the published version using the permanent URI (handle) found on the record page.

This article was made openly accessible by $U$ of $T$ Faculty. Please tell us how this access benefits you. Your story matters. 


\title{
Assessment of the family environment in pediatric neurodisability: a state-of-the-art review
}

\author{
MARJOLIJN KETELAAR ${ }^{1}$ | ALINE BOGOSSIAN² | MICHAEL SAINI ${ }^{3}$ | ANNE VISSER-MEILY ${ }^{1}$ | LUCYNA LACH ${ }^{2}$ \\ 1 Center of Excellence for Rehabilitation Medicine, Brain Center Rudolf Magnus, University Medical Center Utrecht and De Hoogstraat Rehabilitation, Utrecht, the \\ Netherlands. 2 School of Social Work and the Centre for Research on Children and Families, McGill University, Montreal, OC; 3 Factor-Inwentash Faculty of Social \\ Work, University of Toronto, Toronto, ON, Canada.
}

Correspondence to Marjolijn Ketelaar at Center of Excellence for Rehabilitation Medicine, University Medical Center Utrecht and De Hoogstraat Rehabilitation, Rembrandtkade 10, 3583 TM Utrecht, the Netherlands. E-mail: M.Ketelaar-4@umcutrecht.nl

\section{PUBLICATION DATA}

Accepted for publication 18th August 2016. Published online 3rd October 2016

ABBREVIATIONS
$\begin{array}{ll}\text { FACES } & \begin{array}{l}\text { Family Adaptability and Cohe- } \\ \text { sion Evaluation Scale }\end{array} \\ \text { FAD } & \begin{array}{l}\text { McMaster Family Assessment } \\ \text { Device }\end{array} \\ \text { FAM } & \begin{array}{l}\text { Family Assessment Measure } \\ \text { F-COPES }\end{array} \\ \text { Family Coping Strategies Scale } \\ \text { FES } & \text { Family Environment Scale }\end{array}$

The importance of the family environment for the development of children with neurodisabilities is undisputed. The objective of this study is to describe how family environment has been measured in research on families of children with neurodisabilities, in order to support researchers and clinicians to select appropriate methods for use. A three-step approach was used and 13 measures of family environment were identified within 77 studies. Five measures were used most commonly across a majority of studies $(n=50)$. The measures varied considerably in terms of theoretical background, content, subscales, and populations for which they were developed and validated. These measures were used with considerable variability between studies and with a limited range of research respondents, most typically the child's mother. Challenges, opportunities, and suggestions on how to improve the application of family environment measures in research are discussed.
Among clinicians and researchers serving children and young people with neurodisabilities, the importance of the family environment in supporting the developing child is undisputed. It is one of the most proximal systems of influence and an essential aspect of the developmental context. Over the past 30 years, research on the family has grown considerably. ${ }^{1}$ As evidenced by a growth of published handbooks and sourcebooks brimming with techniques and instruments, there is now a wide assortment of measures from which to select, to either clinically assess or evaluate the family. ${ }^{2,3}$ This requires some critical reflection on what aspect of the family is most pertinent to assess/evaluate. Once this is adequately conceptualized, measures can then be reviewed for the extent to which they capture what it is about the family that a clinician or researcher believes to be relevant. The objective of this study is to examine current trends regarding the use of measures of family environment in studies conducted with families of children with neurodisabilities, to critically evaluate those trends, and to make recommendations for future practice and research.

'Neurodisabilities' refers to conditions that comprise 'a group of congenital or acquired long-term conditions that are attributed to impairments of the brain and/or neuromuscular system and create functional limitations.'.(p1105) Children and young people with neurodisabilities represent between $6 \%$ and $9 \%$ of the general population. ${ }^{5}$ While their conditions range in severity and complexity, they and their families are more likely to share experiences with others with similar functional and behavioral limitations, than the limitations caused by the specific disease. In fact, functional limitations across neurodevelopmental disorders are a stronger predictor of family outcomes than the specific diagnoses themselves. ${ }^{6}$ This strongly suggests that challenges lived by these families are compounded by medical complexity; functional limitations such as the child's ability to move, think, hear, or see; as well as difficulties related to his or her regulation of emotions or behaviors. Consequently, on a day-to-day basis, families may grapple with understanding and communicating with the child, all the while navigating uncertainty about what the future holds in a social environment that may not understand them or their child. ${ }^{7,8}$

Families of children with neurodisabilities face challenges that are uniquely different from those of families of children with typical development or even families of children with chronic health conditions. ${ }^{9}$ The needs of their children require them to respond and organize themselves in ways that generate both distress and growth. ${ }^{10}$ For example, parents of children with neurodisabilities are more likely to report higher levels of stress and compromised physical health compared with parents of children with typical development. ${ }^{11-14}$ Concurrently, parents acknowledge that raising children with neurodisabilities can have a positive impact on the family. ${ }^{15}$ The capacity of the family environment to adapt is instrumental to 
ensuring the child's emotional functioning as well as facilitating the child's ability to participate in meaningful activities of daily living. ${ }^{16-18}$

Family systems theory ${ }^{19,20}$ provides a theoretical lens through which to view the family's response and adaptation to raising a child with a neurodisability. In viewing the family as an interactional system, family adaptability is the degree to which the family is flexible and can regain equilibrium in stressful and challenging situations or environments. In families of children with neurodisabilities, this may entail enhancing or adapting patterns of communication both internal and external to the family system, reorganizing roles to meet the demands of caregiving, or negotiating and promoting growth among members in ways that differ from families of children with typical development. Clinicians and researchers should therefore evaluate the extent to which this capacity is reflected in the 'family environment' of children with neurodisabilities.

Consistent with this theoretical perspective, the family is viewed as an interactional system. We were therefore specifically interested in the extent to which measures reflected a focus on interactions and relationships among family members and defined family environment as the quality of interactions and relationships between individuals in the family, and the ways in which individuals within the family unit perceive those interactions and relationships. ${ }^{21}$ In this review, family environment is distinguished from 'parenting' or 'parent well-being' in that it describes the experience of members of the family unit and not of parents' perceptions of themselves as a parent, nor what parents perceive they do when they parent their child. It is also distinguished from assessment or evaluation of parents' experience of stress, coping strategies, psychological/ emotional experience, impact of disability on the family, or social well-being.

Our work draws insight from an overview by Alderfer et $\mathrm{al}^{22}$ who reviewed the psychometric properties and evidence-base of 29 measures of 'family' used in the field of pediatric psychology. In their review, 'family' was operationalized in broad terms and included measures of general family functioning, familial relationships, or families in the context of childhood chronic medical conditions. The selected measures represented a wide variety of concepts (e.g. cohesion, distress, communication, burden, social support) and types of measures (e.g. self-report, observational). Nineteen measures were endorsed as 'well-established', because they fulfilled a number of strict assessment criteria including strong psychometric properties, and 10 measures were rated as 'approaching well-established', fulfilling some but not all assessment criteria. Overall it was concluded that 'these findings are encouraging for the field of pediatric psychology, providing many excellent options when choosing a family assessment measure'. ${ }^{22(\mathrm{p} 1055)}$

Whereas the Alderfer et al. review provided excellent insights into the evidence base and psychometric properties of family measures used in the field of pediatric psychology, ours is a critical review that identifies the strengths

\section{What this paper adds}

- Thirteen measures were used in research to assess family environment.

- Five self-report measures were most commonly used, typically with a single informant.

- None of the measures have been developed specifically for families of children with neurodisabilities.

and limitations of self-report measures used to assess family environment in the context of research on families of children with neurodisabilities. The rationale guiding our review was threefold: (1) although the field of pediatric neurodisability shares some common features with pediatric psychology, it is a distinct field of study with clinicians and researchers who assess/evaluate families of children with neurodisabilities facing challenges that are fundamentally different from that of families of children with chronic health conditions such as asthma or kidney disease; (2) family environment, with a focus on interactions and relationships, is the key mechanism reflecting how families adapt to these challenges; (3) self-report measures are pragmatic and provide an entry into understanding the ways in which individuals within the family unit perceive interactions and relationships within the family.

The objective of this state-of-the-art review ${ }^{23}$ was to explore and describe how family environment has been measured in research conducted with families of children with neurodisabilities to support clinicians and researchers to discern among a wide range of available measures and to select ones that are conceptually consistent with their intended use. It differs from a systematic review of the literature in its emphasis on critical reflection of current trends and applications.

\section{METHOD}

This state-of-the-art review comprised a three-step process to select studies and analyze measures.

\section{Step 1. Search for studies on family environment with a focus on measures used}

First, we used an existing database of studies on families of children with neurodisabilities to search for studies that focused on the family environment in the area of childhood neurodisability. The Parenting Matters! (PM!) systematic review database contains 427 studies published between 1985 and March 2012, addressing the families of children with neurodisabilities (see Appendix SI, online supporting information, for search strategy). Further, a hand-search to identify studies that were published between March 2012 and December 2015 was conducted. This hand-search was conducted in the journals which, based on the previous search, contained the largest number of articles on the family of children with neurodisabilities (see Appendix SI, part B). One of the authors $(\mathrm{AB})$ screened all of the studies and selected studies that focused on families of children with neurodisabilities and that contained a standardized measure to assess 'family' (e.g. family function, family environment, family quality of life, etc.). 


\section{Step 2. From selected studies to a selection of measures}

Second, from the studies included, we identified measures that fulfilled the definition of family environment that we had adopted for this review. From the studies selected in Step 1, the measures were listed, and descriptions of the measures, including subscales, were retrieved. Two authors (MK and $\mathrm{AB}$ ) independently examined the list of measures and rated them for their inclusion or exclusion in this review, based on their fit with the definition of family environment adopted for this review. To be included in this review, at least one dimension or subscale of a measure had to be consistent with this definition, and thus should include issues related to interactions and relationships between individuals in the family. Measures focusing solely on parenting, stress, or parent well-being were excluded.

Then, for the five most frequently used measures, detailed information was obtained from key papers on the development of the measure, manuals accompanying those measures, measurement validation studies (including validation studies specifically on families of children with neurodisabilities), and family measure sourcebooks. ${ }^{2,3} \mathrm{We}$ focused on the following characteristics: (1) the concept(s) it was designed to measure; (2) theoretical underpinnings of the measure; (3) dimensions and subscales; (4) original target population, and whether or not it has been validated for families of children with neurodisabilities; and (5) practical characteristics for use in research and practice.

\section{Step 3. Examples of studies using measures of family functioning}

Finally, to illustrate the use of these measures in research, a purposeful sample of studies were chosen to illustrate how these measures have been applied to families of children with neurodisabilities.

\section{RESULTS}

The first step yielded a total of 77 studies that used 26 unique measures of family that formed the basis of this state-of-the-art review (Fig. S1, online supporting information). Reviewers agreed on the inclusion or exclusion of 21 out of 26 measures. Nine of those 21 were family environment measures. Additional information was sought on the five remaining measures; once obtained, reviewers agreed on the inclusion or exclusion of all 26 measures. Of the 26 measures, 13 were included as they fit our definition of family environment (Table SI, online supporting information). The 13 excluded measures did not measure or did not have subscales assessing interaction between family members, and focused instead on intra- and/or extra-familial stresses and strains, support, or material needs of the family.

\section{Which measures have been used in research in families of children with neurodisabilities?}

The review revealed that most measures were originally developed in the 1970s and 1980s, and that some measures were later revised. The five most commonly used measures were used across a majority of studies $(n=50)$. The most commonly used measure that appeared in 24 studies was the Family Environment Scale (FES), ${ }^{24}$ a measure that focuses on family members' perception of family interactions. Other often used measures were the McMaster Family Assessment Device (FAD), ${ }^{25}$ the Family Adaptability and Cohesion Evaluation Scale (FACES), ${ }^{26}$ the Family Coping Strategies Scale (F-COPES), ${ }^{27}$ and the Family Assessment Measure (FAM) ${ }^{28}$ These five most commonly used measures are described in more detail below and in Table I.

\section{Family Environment Scale (FES)}

The $\mathrm{FES}^{29,30}$ is a 90 -item measure used to assess the social environment, climate or 'personality' of families from a social ecological psychology and general systems theory framework. ${ }^{31}$ The FES is composed of 10 subscales in three dimensions: Relationship, Personal Growth, and System Maintenance (see subscales in Table I). The 90 truefalse item measure can be administered in three forms: the Real Form (Form R) measures respondents' perception of their current family environment, the Ideal Form (Form I) measures respondents' conceptions of an ideal family environment, and the Expectations Form (Form E) asks respondents to indicate their expectations for their family environment in anticipation of future events such as marriage or the birth of a child.

The FES is a self-report measure that is appropriate for individuals 11 years of age/Grade 5 reading level and higher, and each form requires approximately 15 to 20 minutes to complete. It focuses on the entire family, so ideally it is used with as many family members as possible. For each person the subscale raw scores can be determined, and the family's mean raw score can be determined by averaging the subscale raw scores for all members. Raw score to Standard Score conversion tables can be found in the FES Manual. ${ }^{30}$ A higher score is interpreted as a more positive perception of family interactions. Individual scores represent each person's unique view of the family. Several family members' individual scores may also be compared to contrast individual perspectives. Finally, scores from several family members may be combined to provide an overall family profile (e.g. Expression-Oriented, StructureOriented, Conflict-Oriented) and subscale averages can be compared with normative scores. ${ }^{30}$ The FES can be used in clinical settings for individual and family counseling or in clinical research and program evaluation.

The FES has been translated into 15 different languages, has been used widely in research, and validity and reliability have been established in various studies. Information about validity, reliability, and the FES' ability to discriminate between family types at different points of the life cycle is reported in the manual. ${ }^{30}$ An interesting finding in a study conducted with children with chronic illness (e.g. diabetes, cancer, and myelodysplasia) and their families was that there were three higher order dimensions that characterized the family environments of these families and that these were different from dimensions found in families of 
Table I: Characteristics of measures

\begin{tabular}{ll}
\hline Name of measure & Designed to measure \\
\hline Family & Perception of family \\
Environment Scale & interactions in the \\
(FES) & context of the family \\
& social environment: \\
& relationship, personal \\
& growth and system \\
& maintenance
\end{tabular}

Theoretical underpinnings Dimensions/subscales

Based on social ecological 3 dimensions/10 subscales/ psychology and general 90 items

systems theories growth and system maintenance

Cohesion

Expressiveness

Conflict
McMaster Family

Assessment

Device (FAD)
Family Adaptability and Cohesion Scale (FACES IV)
General family

function (structural, organizational, and transactional characteristics of a family)
Perceived and ideal family functioning along two dimensions: cohesion and flexibility
Family Coping Strategies Scale (F-COPES)

Family Assessment Measure (FAM)
Problem-solving and behavioral strategies used by families in response to difficulties or crises

Family's strengths and weaknesses in 7 areas of family functioning
Based on structuralfunctional theory and six theoretical dimensions in the McMaster Model of Family Functioning
Based on Circumplex Model of Couple and Family Systems, which is based on general systems theory
Based on the Double ABCX model of family adjustment and adaptation. It aims to integrate family resources and meaning attributed to family stressors into coping strategies used by families

Based on constructs of a Process Model of family function which is based on the McMaster Model of Family Functioning
Relationship Dimension

Personal Growth Dimension

Independence

Achievement orientation

Intellectual-cultural

orientation

Active recreationa orientation

Moral-religious emphasis

System Maintenance

Dimension

Organization

Control

6 dimensions/7 subscales/

60 items:

Problem-solving

Communication

Roles

Affective responsiveness

Affective involvement

Behavior control

7th subscale (12 items):

General family functioning

(can be used as a short-form

of the FAD to give an overall score of family health)

6 scales along 2 dimensions/ 42 items:

Cohesion dimension:

Balanced cohesion

Disengaged

Enmeshed

Flexibility dimension:

Balanced flexibility

Rigid

Chaotic

FACES-IV includes

companion scales for assessing Family

Communication (10 items)

and Family Satisfaction

(10 items)

5 subscales/29 items:

Acquiring social support

Reframing

Seeking spiritual support

Mobilizing family to acquire

and accept help

Passive appraisal

7 dimensions/50 items:

Task accomplishment

Role performance

Communication

Affective expression

Involvement

Control

Values/norms

For each dimension there are

3 versions, called scale: general scale, self-rating

scale, and dyadic

relationship scale
Population

Original validation: In the initial validation of the measure, normative data collected from a national sample of distressed and non-distressed families. The distressed families included members with psychiatric conditions, alcohol dependence, or members in crisis

Example of other validation samples: Pediatric diabetes, oncology, and

myelodysplasia populations Specific validation with families of children with neurodisabilities?

No

Original validation: The measure was initially validated with a sample of (i) individuals who had family members with psychiatric conditions and

(ii) students in an introductory psychology course.

Specific validation with families of children with neurodisabilities?

No

Original validation: The measure was initially validated with 410 young adults. Factor analysis was conducted with 201 families each of which contained a father, a mother, and an adolescent

Example of other validation samples: Pediatric oncology Specific validation with families of children with neurodisabilities? No

Original validation: The measure was initially validated with high school, undergraduate, and graduate students in psychology and family studies

Specific validation with families of children with neurodisabilities? No

Original validation: Both clinical and nonclinical populations. Clinical families included individuals with major physical disabilities, families of children with emotional difficulties, and families in which a member had a psychiatric condition Specific validation with families of children with neurodisabilities? No 
children without chronic illness. ${ }^{32}$ Based on these findings, another scaling of the FES was proposed with three factors: ${ }^{32}$ Supportive (based on high correlations among the subscales Cohesion, Expressiveness and most subscales of the Personal Growth dimension), Conflicted (based on high correlations among the subscales Conflict, Cohesion, and Organization), and Controlling (based on high correlations among the subscales Control, Achievement Orientation, Moral-Religious Emphasis and Independence). Alderfer et al. ${ }^{22}$ rated the FES as 'approaching wellestablished', based on heterogeneous findings of internal consistency of some of the subscales in some samples. The version of the FES proposed by Kronenberger and Thompson has also been rated as 'approaching wellestablished', as investigators using this scoring method in pediatric populations have rarely reported its psychometric properties. $^{22}$

\section{McMaster Family Assessment Device (FAD)}

The FAD is a 60 -item self-report questionnaire developed to evaluate family function, incorporating structural, organizational, and transactional characteristics of families. ${ }^{25} \mathrm{It}$ contains six dimensions of family function according to the McMaster Model of Family Functioning, ${ }^{33}$ a multidimensional model based on systems, roles, and communication theory to assess the behaviors that produce relational processes within a family. The six dimensions include Problem-solving, Communication, Roles, Affective Responses, Affective Involvement, and Behavior Control. In total there are seven subscales: six dimension subscales and a seventh subscale evaluating the overall general functioning of the family based on a selection of 12 items, which can be used as a shorter version of the FAD. ${ }^{34}$

The FAD is a self-report measure, which is appropriate for adolescents and adult family members (12y or older/ Grade 6 reading level). Respondents rate their (dis)agreement with each item on a 4-point Likert scale on the basis of how well each statement reflects their family. Lower scores on the FAD indicate healthier family functioning. It can be used in both research and clinical practice to (1) screen families experiencing problems, (2) identify specific areas in which families are experiencing problems, and (3) assess change following intervention. It requires approximately 15 to 20 minutes to complete.

The FAD is available in 12 languages. The FAD was initially validated with a sample of individuals whose family members were diagnosed with psychiatric conditions, and students in an introductory psychology course. From early in its development the FAD has been used to predict adjustment in families with a chronically ill member. ${ }^{35}$ The use of the 60-item measure was supported in large clinical, nonclinical, and medical samples. ${ }^{36}$ Alderfer et al. $^{22}$ rated the FAD as 'well-established', because it has been widely used in pediatric samples, has demonstrated excellent internal consistency, and has a large evidence base within peer-reviewed manuscripts.

\section{Family Adaptability and Cohesion Scale (FACES)}

FACES, with FACES IV as the most recent edition (www.facesiv.com), ${ }^{26}$ is a 42 -item self-report questionnaire with 5-point response formats, designed to measure family cohesion and family flexibility, two central dimensions of the Circumplex Model of Couple and Family Systems ${ }^{37}$ that are based on general systems theory. It includes six subscales comprising two Balanced (14 items) and four Unbalanced (28 items) scales along two dimensions: Cohesion and Flexibility. The Cohesion dimension refers to the degree to which family members are separated from or connected to their family; the Flexibility dimension refers to the extent to which a family system is flexible and able to change its structures, role relationships, and relationship rules in response to situational or developmental stress. Based on these two dimensions there are two Balanced (Balanced Cohesion and Balanced Flexibility) and four Unbalanced scales. The Balanced scales are linear scales: the higher the score, the more positive. The four Unbalanced scales assess the low and high extremes of the two dimensions: Disengaged (extreme low Cohesion), Enmeshed (extreme high Cohesion), Rigid (extreme low Flexibility), and Chaotic (extreme high Flexibility). Moreover, FACES-IV also includes two companion scales: Family Communication, a 10-item scale that addresses communication, considered as a facilitating dimension in the Circumplex Model, and Family Satisfaction, a 10-item scale that assess family members' satisfaction with regard to cohesion, flexibility, and communication. Two methods of scoring are available for FACES IV: dimension scoring for clinical use, and ratio scoring for research purposes. The single dimension score for cohesion and flexibility may be used to plot a family on one location on the Circumplex Model of Couple and Family Systems, summarizing information on healthy and problematic aspects in a family. Circumplex ratio scoring is recommended for research to compare groups. It indicates the level of balance versus unbalance perceived by members of a family. A higher ratio (above one) indicates a more balanced family system. $^{26}$

FACES is intended for use with as many family members as possible to capture the complexity of perceptions of the family system. The self-report measure can also be administered by a therapist or counselor with professional training degree (minimum of a Master's level degree) in Psychology or similar area. It is appropriate for individuals 12 years of age/Grade 6 reading level. It can be used in clinical settings for individual and family counseling or in research and program evaluation. It requires approximately 15 minutes to complete.

Alderfer et al. ${ }^{22}$ in 2008 rated the FACES-IV as 'approaching well-established', as data on pediatric samples had not yet appeared in peer-reviewed publications. Since then, the authors have published information about validity and reliability in a student population. ${ }^{26}$ Moreover, in a validation study of FACES-IV with a pediatric oncology 
sample, the internal consistency of the FACES-IV dimensions and predicted associations of the measure with other measures of family functioning were confirmed. ${ }^{38}$ However, findings on the Enmeshed and Rigid items demonstrated inconsistencies and suggested that further improvement of the measure may be warranted for use with families of chronically ill children.

\section{Family Crisis-Oriented Personal Evaluation Scales (F-COPES)}

The F-COPES, ${ }^{27}$ derived from the Double ABCX model of family adjustment and adaptation, was designed to identify problem-solving behaviors and strategies used by families in response to difficulties or crises. The ABCX model posits that a family experiences differing degrees of stress, depending on the stressor event, the family's crisis-meeting resources, and the meaning of the crisis to the family. ${ }^{39}$ The measure focuses on two levels of interaction: internal (the ways in which the family handles difficulties and problems which arise among members of the family) and external (the ways in which the family handles difficulties which arise from the broader social environment but which affect family members). The F-COPES is a 29-item inventory comprising five subscales: (1) acquiring social support (family's ability to acquire support from friends, neighbors, and extended family); (2) reframing (redefining stressful events to make them more manageable); (3) seeking spiritual support; (4) mobilizing family to acquire and accept help; and (5) passive appraisal (ability to accept problematic issues). Individuals rate their (dis)agreement with each item on a 5-point Likert scale on the basis of how well each statement reflects their family. Higher scores indicate more adaptive coping behavior.

F-COPES is a self-report measure, appropriate for individuals who are 12 years of age and/or demonstrate Grade 6 reading level capacity. It can be used in both research and clinical practice (1) to identify problem-solving and behavioral strategies used by families in times of crisis or (2) to assess change over time/after intervention. It requires approximately 20 minutes to complete. F-COPES is available in several languages including English, French, and Hebrew. The measure was initially validated with high school, undergraduate, and graduate students in psychology and family studies. The measure was not included in the review of Alderfer et al. ${ }^{22}$ but validity, stability, and internal consistency have been confirmed, ${ }^{1,27,40}$ also in pediatric populations. $^{41}$

\section{Family Assessment Measure (FAM)}

The FAM, with FAM-III as the most recent edition, ${ }^{28}$ is a self-report assessment of family functioning, based on a Process Model of Family Functioning, an elaboration of the McMaster Model of Family Functioning. ${ }^{33}$ The FAM provides a multilevel assessment of family function across seven dimensions: Task Accomplishment, Role Performance, Communication, Affective Expression, Affective Involvement, Control, and Values and Norms. There are three versions, called scales, each with a different focus, using different wording of questions and different response options, but with the same seven dimensions: (1) a general scale consisting of 50 items, focusing on the family from a systems perspective, and providing an overall rating of family functioning (e.g. 'I don't see how any family could get along better than ours'); (2) a dyadic relationship scale consisting of 42 items, focusing on relationships between various pairs (dyads) in the family (e.g. 'This person and I never see family problems the same way'); (3) a self-rating scale consisting of 42 items, focusing on the individual's perception of his/her own functioning in the family (e.g. 'When I am with my family, I get too upset too easily'). Moreover, each version (general, dyadic, and self-rating) has a corresponding short 14-item version called the Brief FAM, each comprising the two strongest loading items on each of the seven subscales. Respondents are asked to rate their agreement with each item on a 4-point Likert-type scale. Higher scores indicate more perceived difficulties within the specific dimensions. Raw scores can be transformed to standard scores to compare an individual with a nonclinical population. ${ }^{28}$

FAM is a self-report measure, and appropriate for individuals 10 years of age and older. It takes 30 to 45 minutes to complete and is available in English, French, Portuguese, and Spanish. The measure was initially validated with individuals from clinical and nonclinical families. Clinical families included individuals with major physical disabilities, families involved in therapy, families of children with emotional difficulties, and families in which a member had a psychiatric condition. Internal consistency has been confirmed and the FAM is able to discriminate between 'healthy' and 'unhealthy' families. Validity and reliability of the FAM with clinical samples including the families of children with cystic fibrosis, developmental disabilities, and emotional problems, have been reported. ${ }^{28}$ Alderfer et al. ${ }^{22}$ rated the FAM as 'well-established', widely used in pediatric samples, having excellent internal consistency, and a large evidence base within peer-reviewed manuscripts.

\section{Summary of measures Theoretical underpinnings of the measures in our review}

The most-often used measures in our review were developed using different iterations of family systems theories, which are rooted in general systems theories. From these perspectives, individuals cannot be understood in isolation, but in the context of their family system. The measures in our sample were generally informed by models of family functioning: the McMaster Model of Family Functioning ${ }^{33}$ and the Circumplex Model of Couple and Family Systems. ${ }^{37}$ Only the F-COPES measure was based on the Double ABCX model of family adjustment and adaptation, a family stress theory. ${ }^{39}$ Family stress theories are developmental in nature and explore how families respond and adapt to stressors and crises. 


\section{Operationalization of central construct of family environment}

In general, there is both variability and overlap between the constructs evaluated by these measures, with most measures describing the overall construct as 'family functioning'. The measures were selected based on the definition of family environment adopted for this review that focused on interactions and relationships between individuals in the family. In our selection of measures, at least one dimension or subscale of the measure had to be consistent with this definition to be included. Given this criterion, there is both overlap in dimensions and subscales (e.g. Communication, Problem-solving, and Roles being dimensions found in various measures) and unique constructs (e.g. FACES focusing specifically on Cohesion) across measures.

\section{Characteristics and administration of the measures}

All family environment measures in our review used a selfreport format (as opposed to observational rating scales or clinical interviews) that was designed to be administered to multiple members of the family. Some measures (e.g. FES, FACES-IV) had scoring systems that allowed for combining the scores of family members. Although some authors described the measures as ones that could be used to assess change over time or for following-up after an intervention, no specific information on a measure's responsiveness to change was found. The number of items within a measure varied considerably, ranging from 29 items (F-COPES) to 90 (FES) items. This has implications for the amount of time that measures take to complete and therefore respondent burden varies.

The measures in our review were all originally developed for either nonclinical groups or for families who have a member with a psychiatric disorder. Although none of the measures were developed specifically for pediatric populations, Alderfer et al. identified the FAD and FAM as 'well-established' within pediatric populations, meaning that these measures fulfill a number of strict psychometric criteria and have an established evidence-base within the pediatric population. Accordingly, the FES and FACES were rated as 'approaching well-established, fulfilling some but not all psychometric criteria. ${ }^{22}$ Furthermore, use of the FES with families of children with chronic illness has led to the identification of different factor structures. ${ }^{32}$ The F-COPES was not included in the Alderfer et al. review; however, its psychometric properties have been confirmed in pediatric populations. ${ }^{41}$ No studies were found specifically focusing on the psychometric properties of these measures for families of children with neurodisabilities.

\section{How have measures been used in research in families of children with neurodisabilities?}

These five family environment measures were most commonly used in research with families of children with neurodisabilities; they were used in 50 (65\%) of the 77 articles reviewed. The FES was used most often, appearing in 24 studies with variability in the ways in which it was used and adapted. For instance, in several studies, authors limited their use of the measure to a selection of subscales, most prominently the Relationship dimension subscales of cohesion and conflict. Others adapted the measure from its original true-false format to a 4-point Likert scale. Within the studies that used the FES, the Real (R) form was the most commonly used. The FACES measure was used in eight studies, with all versions represented (FACES-I, $n=1$; FACES-II, $n=3$; FACES-III, $n=3$; FACES-IV, $n=1$ ).

Table II provides a purposeful variety of examples of studies, illustrating how these measures have been used. Overall, $n=60$ (78\%) studies were cross-sectional, examining the relationship between family environment and other variables, including the relationship between the family environment and parenting distress or the relationship between child behavior and the family environment at one point in time. Across studies, the measures were used in a variety of ways; at times only one subscale or a selection of subscales was used, and at others the whole measure was used. Irrespective of how and which part of the measure was used, all authors referred to 'family function' as the concept being measured.

Mothers were the primary respondents in two-thirds of the studies, representing $60 \%$ to $100 \%$ of study samples; in 23 studies (29\%) mothers represented $100 \%$ of the study sample, and in 27 studies (35\%) mothers represented between $60 \%$ and $99 \%$ of the study sample. In 14 studies (18\%) mothers and fathers were equally distributed, and in 13 studies (18\%) mothers and fathers' data were pooled and it was not possible to distinguish the proportions of mothers and fathers in the study sample.

\section{DISCUSSION}

The purpose of this state-of-the-art review was to delineate the scope of measures of family environment used in research with families of children with neurodisabilities, to describe theoretical and practical characteristics of oftenused measures, and to describe and discuss how measures of family environment have and can be used in research.

We located a large variety of measures of family environment that have been used in research with families of children with neurodisabilities, although a limited number of measures have been employed more often than others. The FES ( $n=24$ studies), FAD ( $n=9$ studies), and FACES ( $n=8$ studies) were most often used amidst the larger group of measures found in Table SI $(n=13)$. These five most commonly used measures have been described in more detail to highlight their theoretical and practical characteristics (Table I). Although most of these measures were based on (elaborations of) general systems theory, they evaluated both common and unique different constructs in different ways.

Across studies examined for this review, considerable variability was found in which constructs were selected, which subscales were used, and which version of the measure was administered; there was limited variability in which respondents were surveyed (see examples in 
Table II: Examples of studies in which measures of family functioning have been used

\begin{tabular}{|c|c|c|}
\hline Authors & Authors' construct & Aim of study ${ }^{a}$ \\
\hline \multicolumn{3}{|c|}{ Family Environment Scale (FES) } \\
\hline Heiman et al. ${ }^{49}$ & $\begin{array}{l}\text { Family environment - the } \\
\text { social climate of the } \\
\text { family }\end{array}$ & $\begin{array}{l}\text { A } \\
\text { To examine group differences in family } \\
\text { climate among families of children } \\
\text { diagnosed with Asperger syndrome, } \\
\text { families of children with a learning } \\
\text { disability, and families with children with } \\
\text { typical development }\end{array}$ \\
\hline Jandasek et al. ${ }^{50}$ & $\begin{array}{l}\text { Parents' perception of } \\
\text { family conflict and } \\
\text { cohesion }\end{array}$ & $\begin{array}{l}\text { B } \\
\text { To examine parental perceptions of family } \\
\text { conflict and cohesion over time among } \\
\text { families of children with spina bifida. The } \\
\text { measure was used in combination with } \\
\text { an observational tool of observed family } \\
\text { conflict and cohesion }\end{array}$ \\
\hline
\end{tabular}

McMaster Family Assessment Device (FAD) Hsiao $^{51} \quad$ Family functioning

$\begin{array}{ll}\text { McConkey et } \text { al. }^{52} \quad \begin{array}{l}\text { Family functioning } \\ \text { (indication of maternal } \\ \text { well-being) }\end{array} & \end{array}$

Family Adaptation and Cohesion Scale (FACES) Dodd et al.
${ }^{53}$
cohesion and overall family functioning

Xue et $^{5} .^{54} \quad \begin{aligned} & \text { Family functioning as a } \\ & \text { measure of family } \\ & \text { adaptation }\end{aligned}$

Family Crisis-Oriented Personal Evaluation Scales (F-COPES)

Hastings et al. ${ }^{55} \quad$ Family coping strategies A

To assess the contribution of family coping strategies on mothers' positive feelings toward the child with intellectual disabilities

$\begin{array}{cc}\text { Azar and Badr } & \text { Problem-solving and } \\ \text { behavioral strategies } \\ \text { adopted by families }\end{array}$

Family Assessment Measure (FAM)

Thompson et al. ${ }^{57}$ Family functioning/family adjustment

A

To assess the contribution of family coping skills in predicting maternal depressive symptoms among mothers of children with intellectual disabilities

A

To examine the contributions of parenting stress, appraisal of childhood disability, and parental self-esteem on perceptions of family adjustment in families of children with disabilities

A

To examine group differences on perceptions of family relationships among parents of young people with and without learning disabilities
Subscales used?

The FES was adapted from a true-false measure to a Likert-scale type measure (4-point scale). All three dimensions were used, including all subscales except for the 'moral-religious emphasis' subscale form the Personal Growth dimension

Respondents: mothers and fathers Country: Israel

The FES was adapted from a true-false measure to a Likert-scale type measure (4-point scale)

Two subscales from the Relationship dimension were used: Family conflict and Family cohesion

Respondents: mothers and fathers Country: USA

12-item general family function subscale (Chinese adaptation)

Respondents: parents

Country: Taiwan

12-item general family functioning subscale

Respondents: mothers

Countries: N. Ireland, Jordan, Taiwan

Full measure (FACES-II) was used in the study

Respondents: young people, parents

FACES IV; Balanced cohesion, Balanced Flexibility, Family Communication and Family Satisfaction subscales Respondents: mothers and fathers (responses pooled) Country: Singapore

Three subscales: Acquiring social support, Reframing, and Mobilizing family to accept help.

Respondents: mothers

Country: UK

Total score (all subscales)

Respondents: mothers

Country: Lebanon

FAM III-Brief Form

Respondent: mothers and fathers Country: Canada

FAM-III: Dyadic Relationship scale with all 7 subscales

Respondents mothers and fathers and

young people

Country: Israel

\footnotetext{
${ }^{a} A$ : To examine relationship(s) of family functioning with other variables; B: To examine changes over time in family functioning.
}

Table II). For example, most studies surveyed one member of the family, used measures designed to provide real-ideal discrepancy scores but only employed the 'real' score, whereas others compared or combined responses of various family members or administered the measure to a single respondent. This both benefits and constrains the field. On 
the one hand, depending on what aspects of family researchers and practitioners intend to evaluate, there is a menu of possibilities embedded in these measures to consider. On the other hand, this diversity makes comparison of results pertaining to family environment across studies difficult (but not impossible).

An earlier review focusing on the psychometric properties of family measures used in the field of pediatric psychology, ${ }^{22}$ provided an overview of measures, with a broad focus on 'family' measures. We were specifically interested in measures of family environment used in research in families of children with neurodisabilities, as these families face specific challenges. Neurodisabilities represent a broad range of conditions attributed to impairments of the brain and/or neuromuscular system. The impact may include difficulties with movement, cognition, hearing and vision, communication, emotion, and behaviour. ${ }^{4}$ Although one might argue that the assessment of the family environment in specific diagnostic groups would not yield different results, it is important to realize that most measures have been developed and validated for families of children with psychiatric conditions or families of college students, which does not automatically mean that these measures behave or can be used in the same way in other groups. For example, a factor analysis of the FES used in families with a child with a chronic disease ${ }^{32}$ showed that internal consistency of dimensions was not stable. Given that most measures of family environment have not yet been validated with families of children with neurodisabilities, we do not know whether the items that evaluate varying aspects of family environment hang together in the same way for families of children with neurodisabilities as they do for families originally recruited to establish validity of the measure. We concur with the recommendation that, as a minimum standard, researchers should report the internal consistency of the measure for the sample on which they are reporting. This will provide more insight in the interpretation of data from the measure in specific populations.

We were specifically interested in the use of measures focusing on interactions and relationships between family members, because, from a theoretical perspective, this is important for understanding family adaptability in challenging situations. Among the 77 selected studies (Fig. S1), there were 13 measures of family environment, defined as the quality of interactions and relationships between individuals in the family, and the ways in which individuals within the family unit perceive those interactions and relationships. ${ }^{21}$ Thirteen other measures did not meet that definition. Excluded measures focused on different but related conceptualizations of the family such as family strain (e.g. Family Inventory of Life Events [FILE]), ${ }^{42}$ and perceived reactions of a family member to pediatric illness (e.g. Impact on Family Scale [IOF] $){ }^{43}$ Reviews of family measures often focus broadly on 'family' or 'family functioning, ${ }^{22,44}$ without a clear definition of the concept under study. Without this conceptual clarity, it is difficult to know what exactly is being measured and how. We propose that family environment is a conceptually distinct and unique aspect of family function, and so should not be confused with these other concepts.

With a focus on interactions and relationships it is remarkable that the majority of studies in our sample measured family environment from the perspective of one respondent, primarily the mother. We recommend that more attention be paid to all members of the family, and to give greater consideration to how members of the entire family system may be experiencing their family environment. All measures described in this review can be used in this way, yet most studies used primarily mothers as the main respondent; siblings were only rarely involved. Moreover, some measures are structured to measure respondents' perceived and ideal family environment. Discrepancy scores between respondents provide some insight into the extent to which there is agreement in perspectives and could reveal whether the degree of alignment among family members is problematic or not.

Meaningful clinical interventions can only be successful when the uniqueness and diversity of families is acknowledged, a key principle of family-centered care. ${ }^{45,46} \mathrm{~A}$ thoughtful selection of measures can help to identify families needing support, focus interventions, and evaluate change over time with or without an intervention, both in a clinical or research context. All families change, adapt, and realign over time. However, there is a lack of longitudinal research with this population, a phenomenon also highlighted 10 years ago in a review on family functioning among families of children with spina bifida. ${ }^{47}$ Currently, almost no information exists on the evaluative properties of the measures. Future research should focus on their responsiveness to change after interventions or over time, because family environment is not a static concept.

A state-of-the-art review approach was used to explore how the neurodisability field has used family environment measures, and to address current matters in this area. Realizing that it is not a systematic review providing a comprehensive overview of measures available is important in the interpretation of the findings. Potentially interesting measures of family environment could have been missed, when they have not yet been used in research on families of children with neurodisabilities. Moreover, we have chosen to describe five measures in more detail, to provide examples of studies using these often-used measures and to highlight their theoretical and practical characteristics. We realize that by making this selection, measures that might be useful but have not been used often do not gain the attention they might deserve. However, this overview was meant to describe and discuss how measures of family environment have and can be used in research. We aimed to address current matters in this area and provide recommendations to move forward. The examples of measures in this overview may thus be supportive, but not comprehensive at all. We refer to textbooks ${ }^{2,48}$ and more extensive reviews ${ }^{22,44}$ for descriptions of more measures. 
As the family is the central environmental context in children's lives and as family-centered care is the cornerstone principle of practice, there is a need to better understand the family environment in the context of pediatric neurodisabilities to deliver optimal care. There is no straightforward answer to the question of how best to assess family environment. Researchers and practitioners working with families of children with disabilities must first decide what specifically they are interested in measuring, which aspects of the family environment they aim to assess, and who in the family they must include to respond to those questions. By examining descriptions and subscales of measures one gets a richer understanding of the specific aspects of family environment that a measure may capture. The good news is that the family is 'on the agenda'. However, those planning studies should evaluate whether existing measures are reliable and valid specifically for families of children with neurodisabilities across the lifespan. Moreover, research methods in the field should be expanded to capture multiple perspectives of the different members within the family system. This will facilitate better provision of individualized services that meet the unique needs and abilities of each family and family member, and will broaden understanding about what is meant by meaningful family outcomes.

\section{ACKN OWLEDGEMENTS}

We are grateful to Rivka Toonen, Hillian de Haan, and Soh Yon Park for their contribution in the search for measures and related literature. The Canadian Child Health Clinician Scientist Program, Fonds de recherche Quebecois societé et culture, McGill University Centre for Research on Children and Families, and McGill School of Social Work financially supported the work of one of the authors $(\mathrm{AB})$. The authors have stated that they had no interests which might be perceived as posing a conflict or bias.

\section{SUPPORTING INFORMATION}

The following additional material may be found online:

Appendix SI: Sources used for this state-of-the-art review.

Figure S1: Steps in selection of studies and measures.

Table SI: Thirteen family environment measures, the number of studies in our literature search in which they appeared, the construct measured, and sample items.

\section{REFERENCES}

1. Bogossian A, Lach LM, Saini M. Environmental factors: support and relationships. In: Majnemer A, editor. Measures for Children with Developmental Disabilities. London: Mac Keith Press, 2012: 455-83.

2. Corcoran K, Fischer J. Measures for Clinical Practice and Research: A Sourcebook, Volume 1: Couples, Families, and Children. 5th ed. New York: Oxford University Press, 2013.

3. Touliatos J, Perlmetter BF, Straus MA. Handbook of Family Measurement Techniques. Thousand Oaks, CA: Sage Publications Inc, 1989.

4. Morris C, Janssens A, Tomlinson R, Williams J, Logan S. Towards a definition of neurodisability: a Delphi survey. Dev Med Child Neurol 2013; 55: 1103-08.

5. Arim RG, Garner RE, Brehaut JC, et al. Contextual influences of parenting behaviors for children with neurodevelopmental disorders: results from a Canadian national survey. Disabil Rehabil 2012; 34: 2222-33.

6. Miller A, Shen J, Masse LC. Child functional characteristics explain child and family outcomes better than diagnosis: Population-based study of children with autism or other neurodevelopmental disorders/disabilities. Health Rep 2016; 27: 9-18.

7. Reid A, Imrie H, Brouwer E, et al. 'If I knew then what I know now': parents' reflections on raising a child with cerebral palsy. Phys Occup Ther Pediatr 2011; 31: 169-83.

8. Green SE. 'What do you mean "what's wrong with her?"': stigma and the lives of families of children with disabilities. Soc Sci Med 2003; 57: 1361-74.

9. Golfenshtein N, Srulovici E, Medoff-Cooper B. Investigating parenting stress across pediatric health conditions - a systematic review. Compr Child Adolesc Nurs 2016; 39: 41-79.
10. Kearney PM, Griffin T. Between joy and sorrow: being a parent of a child with developmental disability. $7 \mathrm{Adv}$ Nurs 2001; 34: 582-92.

11. Raina $\mathrm{P}$, O'Donnell $\mathrm{M}$, Rosenbaum $\mathrm{P}$, et al. The health and well-being of caregivers of children with cerebral palsy. Pediatrics 2005; 115: e626-36.

12. Parkes J, Caravale B, Marcelli M, Franco F, Colver A. Parenting stress and children with cerebral palsy: a European cross-sectional survey. Dev Med Child Neurol 2011; 53: 815-21.

13. Miodrag N, Burke M, Tanner-Smith E, Hodapp RM. Adverse health in parents of children with disabilities and chronic health conditions: a meta-analysis using the Parenting Stress Index's Health Sub-domain. 7 Intellect Disabil Res 2015; 59: 257-71.

14. Lach LM, Kohen DE, Garner RE, et al. The health and psychosocial functioning of caregivers of children with neurodevelopmental disorders. Disabil Rebabil 2009; 31: $741-52$.

15. Trute B, Hiebert-Murphy D, Levine K. Parental appraisal of the family impact of childhood developmental disability: times of sadness and times of joy. 7 Intellect Dev Disabil 2007; 32: 1-9.

16. Law EF, Fisher E, Fales J, Noel M, Eccleston C. Systematic review and meta-analysis of parent and familybased interventions for children and adolescents with chronic medical conditions. 7 Pediatr Psychol 2014; 39: 866-86.

17. Soref B, Ratzon NZ, Rosenberg L, Leitner Y, Jarus T, Bart O. Personal and environmental pathways to participation in young children with and without mild motor disabilities. Child Care Health Dev 2012; 38: 561-71.

18. Dang VM, Colver A, Dickinson HO, et al. Predictors of participation of adolescents with cerebral palsy: A
European multi-centre longitudinal study. Res Dev Disabil 2014; 36C: 551-64.

19. Bowen $M$. The use of family theory in clinical practice. Compr Psychiatry 1966; 7: 345-74.

20. Reed SK. Treatment of a family whose child has a serious medical problem. In: Titelman P, editor. Clinical Applications of Bowen Family Systems Theory. New York: Haworth Press, 1998: 165-86.

21. Lach L. The family does matter!. In: Ronen GM, Rosenbaum PL, editors. Life Quality Outcomes in Children and Young People with Neurological and Developmental Conditions. London: Mac Keith Press, 2013: 136-53.

22. Alderfer MA, Fiese BH, Gold JI, et al. Evidence-based assessment in pediatric psychology: family measures. 7 Pediatr Psychol 2008; 33: 1046-61.

23. Grant MJ, Booth A. A typology of reviews: an analysis of 14 review types and associated methodologies. Health Info Libr 7 2009; 26: 91-108.

24. Moos RH, Moos BS. Family Environment Scale Manual, 3rd ed. Palo Alto: Consulting Psychologists Press, 1994.

25. Epstein NB, Baldwin LM, Bishop DS. The McMaster Family Assessment Device. 7 Marital Fam Ther 1983; 9: 171-80.

26. Olson D. FACES IV and the Circumplex Model: validation study. 7 Marital Fam Ther 2011; 37: 64-80.

27. McCubbin HI, Olson DH, Larsen AS. F-COPES (family crisis oriented personal evaluation scales). In: McCubbin HI, Thompson AI, editors. Family Assessment Inventories for Research and Practice. Madison, WI: University of Wisconsin-Madison, 1991: 193-207.

28. Skinner H, Steinhauer P, Sitarenios G. Family Assessment Measure (FAM) and process model of family functioning. J Fam Ther 2000; 22: 190-210. 
29. Moos RH, Insel PM, Humphrey B. Family Environment Scale. Palo Alto, CA: Consulting Psychologists Press, 1974.

30. Moos RH, Moos BS. Family Environment Scale Manual. 4th ed. Palo Alto, USA: Consulting Psychology Press, 2009

31. Grotevant HD, Carlson CI. Family Assessment: A Guide to Methods and Measures. New York: The Guilford Press, 1989

32. Kronenberger WG, Thompson RJ. Dimensions of family functioning in families with chronically ill children: A higher order factor analysis of the Family Environment Scale. 7 Clin Child Psychol 1990; 19: 380-88.

33. Epstein NB, Bishop DS, Levin HS. The McMaster model of family functioning. 7 Marital Fam Ther 1978; 4: 19-31.

34. Byles J, Byrne C, Boyle MH, Offord DR. Ontario Child Health Study: reliability and validity of the general functioning subscale of the McMaster Family Assessment Device. Fam Process 1988; 27: 97-104.

35. Miller IW, Ryan CF, Keitner GI, Bishop DS, Epstein NB. The McMaster approach to families: theory, assessment, treatment and research. 7 Fam Ther 2000; 22: 168.

36. Kabacoff RI, Miller IW, Bishop DS, Epstein NB, Keitner GI. A psychometric study of the McMaster Family Assessment Device in psychiatric, medical, and nonclinical samples. 7 Fam Psychol 1990; 3: 431-39.

37. Olson DH, Russell CS, Sprenkle DH. Circumplex model of marital and family systems: VI. Theoretical update. Fam Process 1983; 22: 69-83.

38. Marsac ML, Alderfer MA. Psychometric properties of the FACES-IV in a pediatric oncology population. 7 Pediatr Psychol 2011; 36: 528-38

39. McCubbin HI, Patterson JM. The family stress process - the Double ABCX model of adjustment and adaptation. Marriage Fam Rev 1983; 6: 7-37.

40. McCubbin H, Thompson A, McCubbin M. Family Assessment: Resiliency, Coping and Adaptation. Madison: University of Wisconsin Publishers, 1996.

41. Churchill SS, Villareale NL, Monaghan TA, Sharp VL, Kieckhefer GM. Parents of children with special health care needs who have better coping skills have fewer depressive symptoms. Matern Child Health 7 2010; 14 $47-57$.

42. McCubbin HI, Patterson JM, Wilson LR. FILE - family inventory of life events. In: McCubbin HI, Thompson AI, editors. Family Assessment: Resiliency, Coping and Adaptation: Inventory for Research and Practice. Madison, WI: University of Wisconsin, 1983: 103-78.

43. Stein RE, Jessop DJ. The impact on family scale revisited: further psychometric data. 7 Dev Behav Pediatr 2003; 24: 9-16.

44. Hamilton E, Carr A. Systematic review of self-report family assessment measures. Fam Process 2016; 55: 16-30.

45. King G, Chiarello L. Family-centered care for children with cerebral palsy: conceptual and practical considerations to advance care and practice. $\mathcal{F}$ Child Neurol 2014; 29: 1046-54.

46. Rosenbaum P, Gorter JW. The 'F-words' in childhood disability: I swear this is how we should think!. Child Care Health Dev 2012; 38: 457-63.

47. Holmbeck GN, Greenley RN, Coakley RM, Greco J, Hagstrom J. Family functioning in children and adolescents with spina bifida: an evidence-based review of research and interventions. 7 Dev Behav Pediatr 2006; 27: 249-77.

48. Majnemer A. Measures for Children with Developmental Disabilities. An ICF-CY Approach. London: Mac Keith Press, 2012

49. Heiman T, Zinck LC, Heath NL. Parents and youth with learning disabilities: perceptions of relationships and communication. 7 Learn Disabil 2008; 41: 524-34.

50. Jandasek B, Holmbeck GN, DeLucia C, Zebracki K, Friedman D. Trajectories of family processes across the adolescent transition in youth with spina bifida. 7 Fam Psychol 2009; 23: 726-38.

51. Hsiao C. Family demands, social support and family functioning in Taiwanese families rearing children with Down syndrome. 7 Intellect Disabil Res 2014; 58: 549-59.

52. McConkey R, Truesdale-Kennedy M, Chang MY, Jarrah $\mathrm{S}$, Shukri R. The impact on mothers of bringing up a child with intellectual disabilities: a cross-cultural study. Int 7 Nurs Stud 2008; 45: 65-74.

53. Dodd DC, Zabriskie RB, Widmer MA, Eggett D. Contributions of family leisure to family functioning among families that include children with developmental disabilities. F Leisure Res 2009; 41: 261-86.

54. Xue J, Ooh J, Magiati I. Family functioning in Asian families raising children with autism spectrum disorders: the role of capabilities and positive meanings. 7 Intellect Disabil Res 2014; 58: 406-20.

55. Hastings RP, Allen R, McDermott K, Still D. Factors related to positive perceptions in mothers of children with intellectual disabilities. 7 Appl Res Intellect Disabil 2002; 15: 269-75.

56. Azar M, Badr LK. The adaptation of mothers of children with intellectual disability in Lebanon. 7 Transcult Nurs 2006; 17: 375-80.

57. Thompson S, Hiebert-Murphy D, Trute B. Parental perceptions of family adjustment in childhood developmental disabilities. 7 Intellect Disabil 2013; 17: 24-37.

58. McCubbin HI, Comeau J. FIRM: Family inventory of resources for management. In: McCubbin HI, Thompson AI, editors. Family Assessment Inventories for Research and Practice. Madison: University of Wisconsin-Madison, 1987: 145-60.

59. Olson D, Larsen A, McCubbin HI. Family strengths. In: Olson D, McCubbin HI, Barnes HL, Larsen A, Muxen MJ, Wilson MA, editors. Family Inventories. St. Paul: University of Minnesota Press, 1985: 63-75.

60. Austin JK, Huberty TJ. Revision of the Family APGAR for use by 8-year-olds. Fam Syst Med 1989; 7: 323-27.

61. Roberts CS, Feetham SL. Assessing family functioning across three areas of relationships. Nurs Res 1982; 31: $231-35$.

62. Pless IB, Satterwhite B. A measure of family functioning and its application. Soc Sci Med 1973; 7: 613-20.

63. Park J, Hoffman L, Marquis J, et al. Toward assessing family outcomes of service delivery: validation of a family quality of life survey. 7 Intellect Disabil Res 2003; 47: 367-84. 